\title{
Reduction of Bacteria in Relation to Feeding Regimes When Treating Aquaculture Waste in Fly Larvae Composting
}

\author{
Ivã Guidini Lopes ${ }^{1,2 *}$, Cecilia Lalander ${ }^{2}$, Rose Meire Vidotti1,3 and Björn Vinnerås ${ }^{2}$ \\ ${ }^{1}$ Aquaculture Center of Unesp (Caunesp), São Paulo State University (UNESP), São Paulo, Brazil, ${ }^{2}$ Department of Energy \\ and Technology, Swedish University of Agricultural Sciences, Uppsala, Sweden, ${ }^{3}$ São Paulo Agency of Agribusiness \\ and Technology (APTA), Polo Regional Centro-Norte, Pindorama, Brazil
}

\section{OPEN ACCESS}

Edited by:

Leen Van Campenhout, KU Leuven, Belgium

Reviewed by: Jeroen De Smet,

KU Leuven, Belgium Ine Van Der Fels-Klerx, Wageningen University \& Research,

Netherlands

Moritz Gold,

ETH Zürich, Switzerland

*Correspondence: Ivã Guidini Lopes

ivanguid@gmail.com

Specialty section:

This article was submitted to

Food Microbiology,

a section of the journal

Frontiers in Microbiology

Received: 24 March 2020

Accepted: 19 June 2020

Published: 16 July 2020

Citation:

Lopes IG, Lalander C, Vidotti RM and Vinnerås B (2020) Reduction of Bacteria in Relation to Feeding Regimes When Treating Aquaculture Waste in Fly Larvae Composting.

Front. Microbiol. 11:1616. doi: 10.3389/fmicb.2020.01616
This study evaluated the impact of feeding regimes on process performance and inactivation of microorganisms during treatment of aquaculture waste with black soldier fly (BSF) larvae. In three treatments (T1-T3), a blend of reclaimed bread and aquaculture waste was used as substrate for BSF larvae. In T1, the substrate was inoculated with four subtypes of Salmonella spp. and Escherichia coli (both at $1 \% \mathrm{w} / \mathrm{w}$ ), and offered only once, at the beginning of the 14-day trial. In T2 and T3, the substrate was supplied on three different days, with contaminated substrate provided only the first event in T2 and in all three events in T3. Provision of a lump sum feeding (T1) proved unfavorable for larval growth and process efficiency, but did not affect the microbial reduction effect. The total reduction in Salmonella spp. was approximately $6 \log _{10}$ in T1 and T2, and $3.3 \log _{10}$ in T3, while the total reduction in E. coli was approximately $4 \log _{10}$ in $T 1$ and T2, and $1.9 \log _{10}$ in T3. After removing the larvae, the treatment residues were re-inoculated with Salmonella spp. and E. coli. It was found that the inactivation in both organisms continued in all treatments that originally contained BSF larvae (T1T3), suggesting that antimicrobial substances may have been secreted by BSF larvae or by its associated microbiota.

Keywords: BSF, ecotechnology, hygienization, Escherichia coli, Salmonella Senftenberg, S. Typhimurium, $S$. Typhi, S. Dublin

\section{INTRODUCTION}

Global fisheries and aquaculture production exceeded 170 million tons in 2016. Of this, $47 \%$ was produced exclusively by aquaculture, a fast-growing industry providing high-quality animal protein worldwide (FAO, 2018). Generation of solid organic waste occurs throughout all production steps in aquaculture, from nurseries to fattening stages, at fish processing plants, research centers and up to the final consumer (Love et al., 2015; Lopes et al., 2019). Fish waste (e.g., whole carcasses and body parts) typically contains high nutrient loads, which can be detrimental to the environment if inadequately disposed, causing soil and water contamination (Erondu and Anyanwu, 2005). In addition, as this waste stream decomposes rapidly, its microbial communities multiply during decomposition, thus posing a risk of disease transmission, as these residues may contain pathogens (Ghaly et al., 2010; Sousa et al., 2014). 
It is well established that fish carry a diverse community of microorganisms in their gut and skin (Leroi and Joffraud, 2011). These include autochthonous microbiota and pathogenic bacteria originating from the aquatic environment where the fish are reared and from inadequate processing ( Mol and Tosun, 2011). Cross-contamination may also occur and compromise non-contaminated materials, e.g., when the same processing equipment is used for contaminated and non-contaminated fish (Ghaly et al., 2010). The different microorganisms present include Gram-positive bacteria such as Enterococcus spp. and Clostridium spp. (Leroi and Joffraud, 2011), and Gramnegative bacteria belonging to the Enterobacteriaceae family, such as Escherichia coli and Salmonella spp. (Morris et al., 1970; Marchaim et al., 2003). Under favorable conditions (e.g. moisture and temperature), fish spoilage proceeds from autolytic deterioration to microbial degradation within 2-5 days (Shawyer and Pizzali, 2003).

Sanitization of organic wastes can be achieved by various treatment methods, such as thermophilic composting (Soobhany et al., 2017) and anaerobic digestion (Grudziñsk et al., 2015). A novel treatment using larvae of the black soldier fly (BSF) (Hermetia illucens L.) (Diptera: Stratiomyidae) has also been shown to be promising in relation to the sanitization of different biodegradable waste streams. During treatment by BSF larvae, initial waste volumes can be reduced by up to $85 \%$ (wet basis), while generating two marketable products: a protein-rich larval biomass to be used in replacement of soybean and fishmeal in animal diets (Wang and Shelomi, 2017), and an organic treatment residue that can be used as a soil amendment (Setti et al., 2019), both representing more sustainable alternatives for the transition to a circular economy. Additionally, there is evidence that BSF larvae treatment of organic wastes have an impact on the concentration of selected microorganisms, thus improving its hygiene quality (Erickson et al., 2004; Choi et al., 2012; Lalander et al., 2013).

In a study examining the effect of BSF larvae treatment of chicken manure inoculated with E. coli and S. enterica, Erickson et al. (2004) observed that the presence of larvae accelerated inactivation of both bacteria. However, they also found that, while the observed reductions in microbial levels were significant, they were insufficient to ensure complete safety of the treated manure as a soil amendment. Similarly, Lalander et al. (2013) found significant reductions in Salmonella spp. when treating human feces with BSF larvae, but detected the pathogen in the gut of the larvae at the end of treatment. They recommended an additional processing step for the product to ensure its hygienic quality.

Although several studies have demonstrated the capacity of BSF larvae to inactivate microorganisms, the mechanism behind this inactivation remains poorly understood. Among several existing interactions between BSF larvae and the environment, two possible mechanisms for the inactivation have been suggested: (1) passage through the BSF larvae gut and associated exposure to low $\mathrm{pH}$ (Coluccio et al., 2008); and (2) secretion of antimicrobial substances, such as organic acids and peptides that bind to the bacterial cell wall, by BSF larvae (Choi et al., 2012; Park et al., 2014;
Vogel et al., 2018). Other studies have demonstrated strong interactions between the medium and BSF larvae microbiota, with significant interferences related to biotic and abiotic factors that could lead to distinct microbiological responses in the treatment of wastes as a whole (Wynants et al., 2018; Jiang et al., 2019). The mechanism that contributes most to microorganism inactivation, and whether different feeding regimes generate different results in terms of inactivation, remain to be determined.

Different systems (batch or semi-batch feeding systems) for organic waste treatment using BSF larvae have produced promising results in terms of waste sanitization, in particular for two microorganisms: E. coli, an indicator microorganism of fecal contamination, and Salmonella spp., a zoonotic pathogen (Hasan et al., 2019). Erickson et al. (2004) observed the inactivation of these microorganisms in a batch-mode system using different manures as growth substrate, and observed significant reductions in the populations of both $(1.5-5 \log$ for E. coli and $0.5-4.0$ $\log$ for Salmonella spp. at varying temperatures). In a continuous BSF larvae reactor to which substrate was added three times a week and small larvae twice a week, Lalander et al. (2015) obtained significant reductions in Salmonella spp., but observed small inactivation in thermotolerant coliforms, where E. coli is the dominant species (Hachich et al., 2012). These findings suggest that there could be an impact of treatment system, the time in the treatment at which contaminated waste is added and feeding regime, on microorganism inactivation in BSF larvae treatment.

The aims of this study were to investigate the impact of feeding regimes and time of bacterial contamination on inactivation of selected microorganisms, and assess whether the treatment residue had antimicrobial properties.

\section{MATERIALS AND METHODS}

\section{Materials}

Reclaimed bread of different brands and nutritional composition was donated by a local distribution company in Uppsala, Sweden $\left(\right.$ Fazer $\left.^{\circledR}\right)$. The selected model substrate for aquaculture waste (Oncorhynchus mykiss carcasses) was supplied by a commercial fish farm (Nordic Trout ${ }^{\circledR}$ ) located in Mora (Sweden). Upon collection, the bread was manually shredded and placed inside plastic bags, while the aquaculture waste was milled in a meat grinder, homogenized, and placed in plastic bags. Both materials were kept at $-18^{\circ} \mathrm{C}$ until use.

In a pre-trial performed before the start of the experiment, it was observed that the $\mathrm{pH}$ of the substrate (aquaculture waste and bread) declined significantly $(<4.0)$ after approximately $72 \mathrm{~h}$. This confounded the aim of the study, as pathogen survival may be jeopardized by low $\mathrm{pH}$ conditions. In order to avoid this drop in $\mathrm{pH}$, the bread was moistened with a phosphate buffer solution ( $\mathrm{pH}$ 7.2; SVA, Sweden) prior to the beginning of the experiment, to a moisture content of approximately $65 \%$.

The larvae used in the experiments were obtained from a colony that has been running continuously since 2015, located at the Swedish University of Agricultural Sciences (SLU, Uppsala). 
Newly hatched larvae were reared on a substrate containing chicken feed (Granngården Hönsfoder Start) 20\% dry matter, $\mathrm{DM}$ ) and larvae treatment residues (1:1 ratio), for approximately 7 days. Larvae (1.2 mg wet mean weight) were separated by sieving ( $1 \mathrm{~mm}$ mesh), and three batches of 100 larvae were counted and weighted for batch weight estimation.

The pathogens used in this experiment were four serotypes of the Gram-negative bacteria Salmonella enterica (S. Senftenberg, S. Typhimurium, S. Typhi, and S. Dublin), and E. coli ATCC 13706, a specific microorganism used as an indicator of fecal contamination. The Gram-positive bacteria Enterococcus spp. was also evaluated throughout the study. It was not inoculated into the substrate, but was already present in the fish carcasses, at an approximate concentration of $10^{5} \mathrm{CFU} \mathrm{g}^{-1}$. E. coli (unknown strain) was also present in the carcasses at low concentrations $\left(10^{3}-10^{4} \mathrm{CFU} \mathrm{g}^{-1}\right)$ - which would be further diluted by the addition of bread - thus we chose to inoculate this bacteria in the substrate in order to begin with higher concentrations and more stable populations.

Bacterial inoculate solutions were prepared according to the following procedure: the selected bacterial strains were grown at $37^{\circ} \mathrm{C}$ for $2 \mathrm{~h}$, at 200 revolutions per minute (rpm), in $5 \mathrm{~mL}$ nutrient broth (Oxoid AB, Sweden). This concentrated solution was diluted in $45 \mathrm{~mL}$ of nutrient broth and kept in the same conditions for $24 \mathrm{~h}$. Finally, the bacterial solution was centrifuged at $4500 \mathrm{rpm}$ for $15 \mathrm{~min}$ at $15^{\circ} \mathrm{C}$, and the pellet was collected and dissolved in $50 \mathrm{~mL}$ of Tween buffer (buffered $\mathrm{NaCl}$ peptone water with Tween 80 at $\mathrm{pH}$ 7; SVA, Sweden). The acquired concentrations of Salmonella spp. and E. coli in these concentrated solutions were approximately $10^{7}$ and $10^{6} \mathrm{CFU} \mathrm{g}^{-1}$, respectively, being determined by plating different diluted solutions originated from the concentrated solutions. The inoculation was performed directly on the combined substrate, at a rate of $1 \% w / w$, before it was added to the treatments.

\section{Experimental Set-Up and Sampling}

Two experiments were performed, aimed at: (1) determining the impact of feeding regime on BSF larvae treatment; and (2) investigating the inactivation potential of BSF larvae in the treatment of contaminated wastes, in order to evaluate the antimicrobial potential of the treatment residue, which serves as an indication of the presence of antimicrobial substances. The first experiment consisted of a control (CT) and three treatments (T1-T3), representing different feeding strategies. In $\mathrm{T} 1$, the feeding substrate was inoculated with four salmonella strains and E. coli and added once, on the first day of the experiment. In T2 and T3, the substrate was added three times, on day 1 , day 4 , and day 7 , but was only inoculated on the first feeding (day 1) in T2, whereas the substrate in all three feedings was inoculated in T3. The control treatment followed the same protocol as in T1, but without addition of larvae, in order to determine the impact of these organisms (Figure 1).

The experimental units used in the first experiment were plastic containers $(21 \times 17 \times 11 \mathrm{~cm})$ covered with netting to prevent escaping of larvae. Three replicates per treatment were assembled. A total of 1000 larvae were placed inside each unit, giving an approximate density of 4 larvae $\mathrm{cm}^{-2}$, and a feeding rate of $0.25 \mathrm{~g}$ volatile solids (VS) larvae $^{-1}$ was applied $(80 \%$

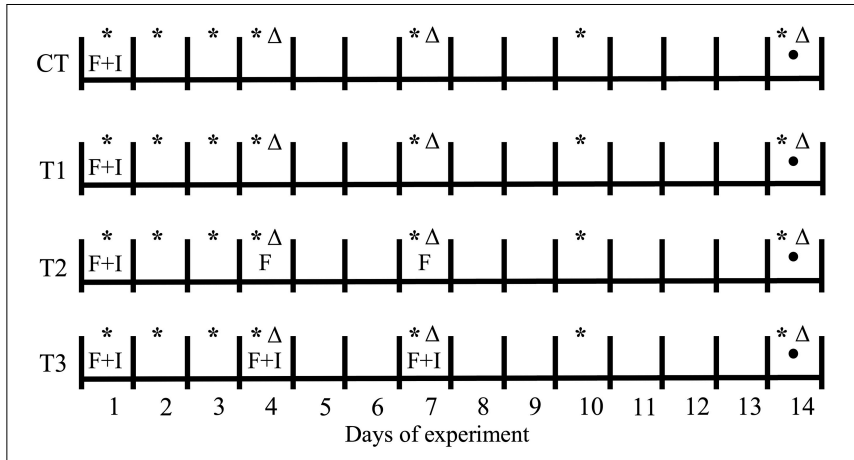

FIGURE 1 | Schematic representation of the feeding and pathogen inoculation protocols throughout the first 14-day experiment with BSF larvae. $\mathrm{CT}$, treatment without BSF larvae; F, feeding event; I, inoculation of pathogens; ( $\left.{ }^{\star}\right) \mathrm{pH}$ measurement; $(\Delta)$ evaluation of total ammonium nitrogen $(\mathrm{TAN})$ in the treatment residues; $(\bullet)$ total nitrogen $\left(\mathrm{N}_{\mathrm{T}}\right)$ measurement.

aquaculture waste, $20 \%$ bread waste on wet basis). The $\mathrm{pH}$ of the treatment residues was measured on days $1-4,7,10$, and 14 , as was the total ammonium nitrogen (TAN) concentration. On day 14 of the experiment, the larvae were manually separated from treatment residues and one sample of approximately $30 \mathrm{~g}$ was collected per replicate (larvae and residue) for analysis of DM, VS, and total nitrogen $\left(\mathrm{N}_{\mathrm{T}}\right)$ content (Figure 1).

In the second experiment (called regrowth trial), all treatments considered in the first trial, including CT, were included. Triplicate, $5 \mathrm{~g}$ samples, of the treatment residues (materials remaining in the experimental units after the first experiment) from each replicate were collected using a sterile spoon, individually transferred to $50 \mathrm{~mL}$ Falcon tubes, and inoculated with the same concentrated solutions of Salmonella spp. and $E$. coli as were used in the first experiment, with an approximate concentration of $10^{6} \mathrm{CFU} \mathrm{g}^{-1}$ and $10^{5} \mathrm{CFU} \mathrm{g}^{-1}$, respectively. After 24, 72, and $120 \mathrm{~h}$, the concentrations of these bacteria were assessed, as described ahead. Both experiments were conducted in a Class II microbiological laboratory. The mean temperature inside the laboratory was $28.8 \pm 1.8^{\circ} \mathrm{C}$ throughout the experiments.

\section{Physico-Chemical Analysis}

All samples of larvae and treatment residues $(30 \mathrm{~g})$ were dried at $105^{\circ} \mathrm{C}$ for $14 \mathrm{~h}$ for $\mathrm{DM}$ determination and combusted at $550^{\circ} \mathrm{C}$ for $6 \mathrm{~h}$ for total VS evaluation. For $\mathrm{pH}$ measurement, $5 \mathrm{~g}$ of treatment residues from each experimental unit were dissolved in $20 \mathrm{~mL}$ of deionized water and agitated in a vortex mixer for $2 \mathrm{~min}$. After $1 \mathrm{~h}$ at room temperature, the $\mathrm{pH}$ was measured using a bench $\mathrm{pH}$ meter (InoLab $\mathrm{pH}$ level 1).

For $\mathrm{N}_{\mathrm{T}}$ analysis, $0.5 \mathrm{~g}$ of sample was diluted in $15 \mathrm{~mL}$ of concentrated $\mathrm{H}_{2} \mathrm{SO}_{4}$ and brought to a "rolling boil" for approximately $20 \mathrm{~min}$ on a heating plate, and cooled to room temperature. A $1 \mathrm{~mL}$ sample from this mixture was diluted 50 times in deionized water, and the $\mathrm{pH}$ was neutralized to a range of $4-7$, using a $10 \mathrm{M} \mathrm{NaOH}$ solution. A $10 \mathrm{~mL}$ sample of this solution was digested following the instructions of the analysis kit Spectroquant ${ }^{\circledR}$ Crack-Set 20 (1.14963.0001), and the 
nitrate concentration was measured using a spectrophotometer at $340 \mathrm{~nm}$, following the provider's instructions of the kit Spectroquant ${ }^{\circledR}$ Nitrate Test (1.09713.0002). For analysis of TAN concentrations in treatment residues, $1 \mathrm{~g}$ of sample was dissolved in $4 \mathrm{~mL}$ of deionized water, mixed in a vortex mixer for approximately $2 \mathrm{~min}$, and the concentration was measured using a spectrophotometer at $640 \mathrm{~nm}$, following the instructions of the provider of the analysis kit Spectroquant ${ }^{\circledR}$ Ammonium Test (1.00683.0001).

\section{Microbiological Analysis}

Microbial concentrations were assessed on a daily basis in the first experiment and on days 1, 3 and 5 in the second experiment, according to the following procedure: $5 \mathrm{~g}$ of treatment residues were dissolved in $45 \mathrm{~mL}$ of Tween buffer (this dilution was named $10^{-1}$ ), and serial dilutions were prepared from this concentrated solution after a 15 min resting period. A $100 \mu \mathrm{L}$ volume of the selected dilution was spread on xylose lysine desoxycholate agar (XLD) with novobiocin (Oxoid AB, Sweden) for Salmonella spp. enumeration, and on chromocult coliform agar for E. coli enumeration, both incubated at $37^{\circ} \mathrm{C}$ for $24 \mathrm{~h}$. A $100 \mu \mathrm{L}$ volume was also spread on Slanetz-Bartley agar (Oxoid $\mathrm{AB}$, Sweden) and incubated at $44^{\circ} \mathrm{C}$ for $48 \mathrm{~h}$ for Enterococcus spp. enumeration (only the first experiment). Three plates were prepared daily for each of the pathogens evaluated per replicate in the first experiment and on the three evaluation days in the regrowth experiment. In order to reduce the detection limits of Salmonella spp. and E. coli concentrations, a $200 \mu \mathrm{L}$ volume of the concentrated solution $\left(10^{-1}\right)$ was spread on five plates for each sample and enumerated with a detection limit of $10 \mathrm{CFU}$ $\mathrm{mL}^{-1}$.

\section{Calculations}

DM losses and $\mathrm{N}$ volatilization were assessed by deducting the amount found in the residues and larvae at the end of the experimental period from the total amount added to the treatment. Survival rates were calculated in T1, T2, and T3, and process performance was evaluated based on material reduction, bioconversion ratio (percentage of substrate converted into insect biomass), and protein conversion ratio (proportion of added protein converted into larval protein), all presented in percentage.

The material reduction was calculated as:

$$
\text { Material reduction }=1-\frac{\mathrm{m}_{\mathrm{DM} r e s}}{\mathrm{~m}_{\mathrm{DM} u b}}
$$

where $\mathrm{m}_{\mathrm{DM} \text { res }}$ and $\mathrm{m}_{\mathrm{DM} \text { sub }}$ are dry mass of final residues and initial substrate, respectively.

The bioconversion ratio (BCR) on dry matter basis was calculated as:

$$
\mathrm{BCR}=\frac{\mathrm{m}_{\text {DMlarvae }}}{\mathrm{m}_{\text {DMsub }}} \times 100
$$

where $m_{\text {DMlarvae }}$ is dry mass of larvae at the end of the experiment.
The protein conversion ratio (PCR) was calculated as:

$$
=\frac{\mathrm{m}_{\text {DMlarvae }} \times \% \operatorname{Pr}_{\text {larvae }}}{\mathrm{m}_{\text {DMsub }} \times \% \operatorname{Pr}_{\text {sub }}} \times 100
$$

where $\% \operatorname{Pr}_{\text {larvae }}$ and $\% \operatorname{Pr}_{\text {sub }}$ are total percentage of crude protein (DM basis) in larvae and initial substrate, respectively.

A further three indices were used to assess pathogen inactivation: inactivation rate constant $(k)$, which reveals the $\log _{10}$ reduction per time unit $\left(\log _{10} \mathrm{~d}^{-1} \mathrm{~h}^{-1}\right)$; decimal reduction $\left(\mathrm{D}_{90}\right)$, representing the time (days) needed for a $1 \log _{10}$ (90\%) reduction in the microorganisms initially present in the contaminated material; and total logarithmic pathogen reduction ( $\Delta$ LogRed), which represents the total pathogen inactivation from beginning to the end of the experimental period.

Rate constant $k$ was calculated as:

$$
\mathrm{k}=\frac{\left(\log _{10} \mathrm{~N}_{\mathrm{t}}-\log _{10} \mathrm{~N}_{0}\right)}{\left(\mathrm{N}_{\mathrm{t}}-\mathrm{N}_{0}\right)}
$$

where $\mathrm{N}_{t}$ and $\mathrm{N}_{0}$ are bacterial concentration at time $t$ and at the beginning, respectively.

$\mathrm{D}_{90}$ was then calculated as:

$$
\mathrm{D}_{90}=\left(\frac{-1}{\mathrm{k}}\right)
$$

$\Delta$ LogRed was calculated as:

$$
\Delta \operatorname{LogRed}=\log _{10}\left(\frac{\mathrm{CM}_{\mathrm{at} t=0}}{\mathrm{CM}_{\text {at.out } t=i}}\right)
$$

where $\mathrm{CMat}_{t=0}$ is the estimated initial concentration in treatment residues, and CMat.out $t=i$ is the final concentration at time $i$.

\section{Statistical Analysis}

Statistical analyses were performed using $\mathrm{R}$ software, version 3.5.3 (R Core Team, 2019), and GraphPad Prism, version 8.2.1. The assumptions of normality of error (Shapiro-Wilk's test) and homoscedasticity of variance (Levene's test) were verified for all process efficiency and pathogen inactivation data. One-way analysis of variance (ANOVA) with 95\% confidence interval was performed to compare larval growth and process efficiency parameters, and the variables relating to pathogen inactivation. When significant differences were found, a Tukey post hoc test was performed at 5\% significance level, to look for differences between treatments in the variables analyzed. Linear regressions were performed to assess the effect of time on pathogen inactivation.

\section{RESULTS}

\section{Process Efficiency}

The substrate biomass reduction exceeded 65\% (DM basis) in all treatments containing larvae, which was significantly higher 
than in the control treatment (CT) without larvae (Table 1). Larvae growth also differed significantly between treatments. After 14 days, larvae fed only once at the beginning of the trial (T1) were on average 35\% lighter than larvae fed three times (T2 and T3). Hence, the bioconversion and protein conversion ratios were approximately 30 and $20 \%$ lower, respectively, in T1 than in T2 and T3. Larval survival and crude protein (\%) did not vary significantly between treatments (Table 1 ). The difference in bacteria inoculation regime between T2 and T3 (where T3 received Salmonella spp. and E. coli at each feeding and T2 only at first feeding) did not affect the parameters evaluated. The larvae recovered at day 14 were all pre-pupae in all trials.

The $\mathrm{pH}$ of the feeding substrate at the beginning of the experiment was around 6.8, while at the end of the experiment it varied from 6.1 (CT) to 6.8 (T1), being significantly higher in $\mathrm{T} 1$ in comparison to other treatments. DM loss was higher in $\mathrm{T} 1$, where a single batch of substrate was supplied on the first day, than in T2 and T3. In all treatments, the remaining residues were dry after 14 days, with a DM content of 80$88 \%$. The $\mathrm{N}_{\mathrm{T}}$ concentrations in the treatment residues were not significantly different between treatments with larvae, but $\mathrm{N}$ volatilization was significantly higher $(51 \%)$ in T1 than in T2 and T3 (38\%) (Table 2).

The TAN concentrations increased with time in all treatments. Significant differences between treatments were found only at day 14 , when treatments containing BSF larvae showed higher TAN concentrations than CT (Figure 2).

\section{Pathogen Inactivation}

The concentrations of Salmonella spp. and E. coli were significantly reduced in all treatments after 14 days, while Enterococcus spp. concentration was not reduced in any of the treatments. Additionally, the differences between feeding regimes resulted in differences in microbial reduction patterns (Figure 3). The initial concentration of Salmonella spp. and E. coli in the inoculated substrate was approximately $10^{7}$ and $10^{6} \mathrm{CFU} \mathrm{g}^{-1}$, respectively, in all treatments. At the first day post-inoculation, increases of approximately $1 \log _{10}$ were found for both bacteria in all treatments, while Enterococcus spp. populations increased by $1 \log _{10}$ during the 14 days of the experiment (Figure 3 ).

The reduction in both Salmonella spp. and E. coli populations started within approximately 1 week of treatment and continued until the end of the experiment (Figure 3). In T3, where inoculated substrate was added three times, the concentrations of the evaluated microorganisms increased on subsequent days. However, the reduction in Salmonella spp. and E. coli in T3 at the end of the experiment was approximately $2.6 \log _{10}$ and $2.2 \log _{10}$ lower, respectively, than in the other treatments containing BSF larvae (Figure 3).

The reduction of Salmonella spp. was $5.8 \log _{10}$ in T1, $6.2 \log _{10}$ in T2, and $3.4 \log _{10}$ in T3, while the reduction in the control (CT) with no larvae was $0.4 \log _{10}$ (Table 3$)$. The reduction rate $\left(k ; \log _{10}\right.$ CFU g ${ }^{-1}$ day $^{-1}$ ) was similar over time for both Salmonella spp. and E. coli in T1 and T2, but significantly faster than in the control (Table 3). Similarly, the decimal reduction $\left(\mathrm{D}_{90}\right)$ calculations

TABLE 1 | Efficiency of treatment of aquaculture waste and bread using black soldier fly (BSF) larvae.

\begin{tabular}{|c|c|c|c|c|}
\hline & CT & T1 & T2 & T3 \\
\hline Bioconversion ratio (\%) & - & $16.7 \pm 2.2^{b}$ & $24.2 \pm 1.5^{\mathrm{a}}$ & $24.3 \pm 0.4^{a}$ \\
\hline Protein conversion ratio (\%) & - & $14.3 \pm 3.1^{b}$ & $19.2 \pm 1.8^{a}$ & $18.1 \pm 1.0^{\mathrm{a}}$ \\
\hline Material reduction (\%) & $35.9 \pm 5.6^{b}$ & $70.1 \pm 2.6^{\mathrm{a}}$ & $65.6 \pm 1.9^{a}$ & $66.2 \pm 2.1^{\mathrm{a}}$ \\
\hline Final weight (mg) & - & $109.0 \pm 13.0^{b}$ & $165.0 \pm 23.9^{a}$ & $171.9 \pm 12.7^{a}$ \\
\hline Larval CP (\%DM) & - & $47.6 \pm 4.9$ & $44.1 \pm 2.3$ & $41.5 \pm 3.1$ \\
\hline Survival (\%) & - & $86.1 \pm 2.7$ & $93.6 \pm 10.7$ & $90.1 \pm 5.7$ \\
\hline
\end{tabular}

CP, larval crude protein; CT, wastes inoculated with pathogens without larvae; T1, larvae fed once with inoculated wastes; T2, larvae fed three times, with wastes

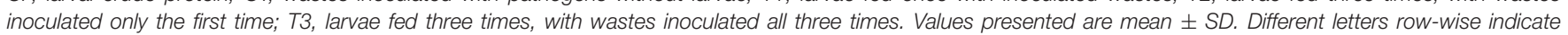
significant differences $(p<0.05)$ between treatments.

TABLE 2 | Physico-chemical characteristics of the treatment residues obtained when black soldier fly (BSF) larvae were fed aquaculture waste and bread, and losses of dry matter and nitrogen after 14 days of treatment.

\begin{tabular}{|c|c|c|c|c|}
\hline & CT & T1 & T2 & T3 \\
\hline Residue DM (\%) & $88.4 \pm 1.3^{a}$ & $83.2 \pm 2.0^{b}$ & $79.1 \pm 2.3^{b}$ & $82.2 \pm 0.4^{b}$ \\
\hline Residue VS (\%) & $94.5 \pm 0.9^{a}$ & $91.4 \pm 1.2^{\mathrm{ab}}$ & $89.7 \pm 1.7^{b}$ & $89.6 \pm 0.8^{b}$ \\
\hline DM loss (\%) & $35.9 \pm 5.6^{b}$ & $53.4 \pm 0.5^{a}$ & $41.4 \pm 2.4^{b}$ & $41.9 \pm 1.9^{b}$ \\
\hline $\mathrm{N}_{\mathrm{T}}\left(\mathrm{g} \mathrm{kg}^{-1}\right)$ & ND & $24.3 \pm 1.3$ & $24.4 \pm 0.3$ & $26.0 \pm 1.7$ \\
\hline N volatilization (\%) & ND & $51.3 \pm 1.3^{a}$ & $38.8 \pm 1.6^{b}$ & $37.9 \pm 0.9^{b}$ \\
\hline Final TAN (mM kg $\left.{ }^{1}\right)$ & $11.3 \pm 2.5$ & $12.9 \pm 1.9$ & $13.1 \pm 6.8$ & $12.3 \pm 3.8$ \\
\hline Initial pH & $6.7 \pm 0.1$ & $6.8 \pm 0.1$ & $6.8 \pm 0.0$ & $6.9 \pm 0.1$ \\
\hline Final pH & $6.1 \pm 0.2^{\mathrm{c}}$ & $6.8 \pm 0.1^{a}$ & $6.5 \pm 0.1^{b}$ & $6.4 \pm 0.1^{b}$ \\
\hline
\end{tabular}

DM, dry matter; VS, volatile solids; NT, total nitrogen; TAN, total ammonium nitrogen; ND, not determined; CT, wastes inoculated with pathogens without larvae; T1,

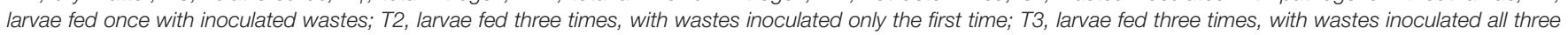
times. Values presented are mean $\pm S D$. Different letters row-wise indicate significant differences $(p<0.05)$ between treatments. 


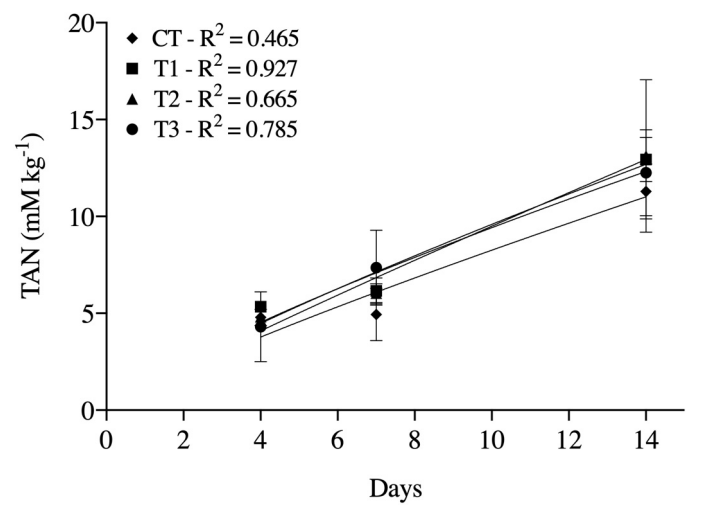

FIGURE 2 | Total ammonium nitrogen (TAN) generated at days 4, 7, and 14 in treatment of aquaculture waste and bread with black soldier fly (BSF) larvae. CT, wastes inoculated with pathogens without larvae; T1, larvae fed once with inoculated wastes; T2, larvae fed three times, with wastes inoculated only the first time; T3, larvae fed three times, with wastes inoculated all three times. $R^{2}$ values are coefficient of determination of the regression lines fitted for each treatment.

revealed that the required time to reduce Salmonella spp. and E. coli populations by $90 \%\left(1 \log _{10}\right)$ was 2.4 days and $3.5-4.5$ days in $\mathrm{T} 1$ and $\mathrm{T} 2$, respectively.

Based on the $\mathrm{D}_{90}$ and $k$ values obtained for $\mathrm{T} 3$, a $90 \%$ reduction in both Salmonella spp. and E. coli from the first to last day of experiment took twice as long as in T1 and T2. Since T3 received inoculated substrate again on days 4 and 7 , additional calculations of $\mathrm{D}_{90}$ and $k$ were performed to assess the inactivation potential of this particular feeding regime. The $\mathrm{D}_{90}$ value from the day post final feeding (day 8) to the final day (day 14) for Salmonella spp. and E. coli was found to be lower than the value based on the concentrations found on days 1 and 14 of the experiment. Similarly, the $k$ was found to be lower, 0.291 and $0.198 \log _{10} \mathrm{CFU} \mathrm{g}^{-1} \mathrm{day}^{-1}$ for Salmonella spp. and E. coli, respectively (Table 3 ).

\section{Regrowth Trial}

The regrowth of microorganisms in the treatment residues (without larvae) in all treatments was evaluated for the four
Salmonella strains and E. coli. The initial achieved concentration of Salmonella spp. and E. coli was approximately $10^{6}$ and $10^{5} \mathrm{CFU}$ $\mathrm{g}^{-1}$, respectively. After 3 days, no reduction was observed for neither of these microorganisms. However, after 5 days, a reduction of approximately $2.5 \log _{10}$ was observed in the treatments that previously had larvae (T1, T2, and T3), while the concentration remained unchanged in the control that had no had BSF larvae (CT). The total reduction in E. coli was similar to that in Salmonella spp. on residues from T1 and T2, as revealed by the $\Delta \log _{10}$ Red and $k$ values after 5 days of the experiment. However, the total reduction on residues from T3 was significantly lower for $E$. coli (total reduction of $1.8 \log _{10}$ ), while an increased concentration was found for the control treatment residue after 5 days (Table 4).

\section{DISCUSSION}

\section{Efficiency of BSF Larvae Treatment in Different Feeding Regimes}

The proportion between aquaculture and bread waste was adopted based on the results obtained by Lopes et al. (2020), whom observed that the addition of more than $25 \%$ of aquaculture waste to bread makes the treatment of this waste unfeasible. Supplying aquaculture-bread wastes as feeding substrates following different protocols (T1-T3) resulted in differences in growth and bioconversion ratios of BSF larvae, but did not affect survival of the larvae. Larvae in treatments T2 and T3 gained more weight than those in T1, which resulted in lower bioconversion ratio and protein conversion ratio (DM basis) in T3. However, the substrate biomass reduction was similar $(\sim 65 \%)$ in all treatments containing larvae, indicating that more of the material was microbially degraded with only one substrate supply (T1), and that BSF larvae more efficiently converted a larger proportion of the substrate when three feedings were performed (T2 and T3).

Physico-chemical changes during fish waste microbial spoilage have been shown to result in lipid oxidation and protein degradation, through which $\mathrm{N}$ is lost by volatilization (Ghaly et al., 2010). Our results support this hypothesis, as $\mathrm{N}$ volatilization was higher in T1 than in T2 and T3 (Table 2).
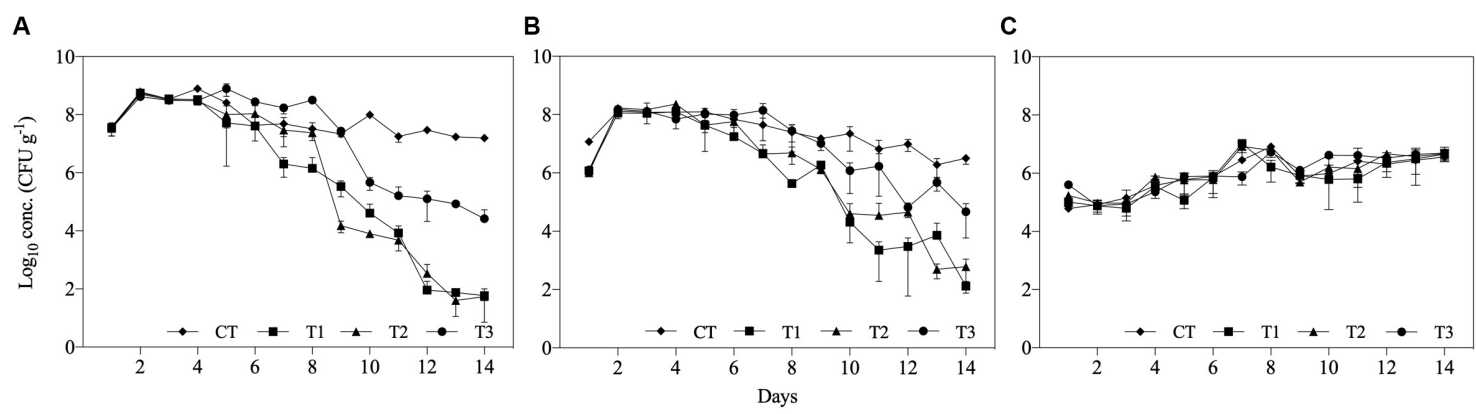

FIGURE 3 | $\log _{10}$ concentrations (CFU g ${ }^{-1}$ ) of (A) Salmonella spp., (B) Escherichia coli, and (C) Enterococcus spp. over 14 days of treatment of aquaculture waste and bread treated with black soldier fly (BSF) larvae. CT, wastes inoculated with pathogens without larvae; T1, larvae fed once with inoculated wastes; T2, larvae fed three times, with wastes inoculated only the first time; T3, larvae fed three times, with waste inoculated all three times. 


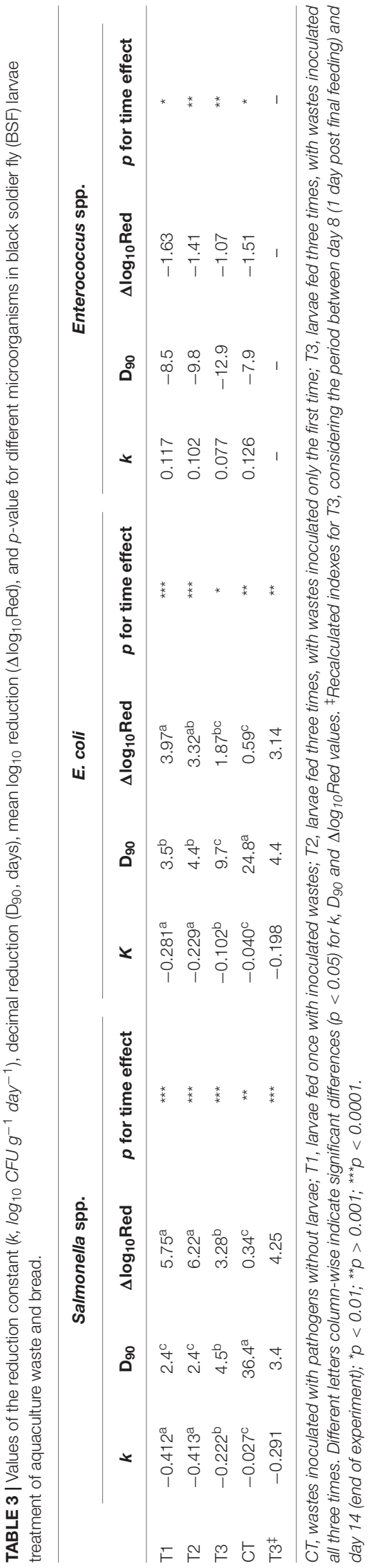

Therefore, the slower BSF larvae growth in T1 could have been caused by nutrient imbalance in the degraded substrate, or by increased bacterial respiration in the substrate. In contrast, Banks et al. (2014) observed larger final body weight, but slower growth, of BSF larvae fed feces substrate in a lump sum rather than every two days. They concluded that aging feces had lower nutritional quality than fresh feces, and therefore the BSF larvae consumed larger amounts of the substrate in order to compensate for this deficiency. Based on the obtained results, the treatment of aquaculture waste is better performed when three batches of the substrate is supplied instead of only once.

\section{Inactivation of Microorganisms}

Escherichia coli is one of the most commonly used indicator organisms for fecal contamination (Carlos et al., 2010), and it occurs naturally in decaying carcasses of different fish species (Leroi and Joffraud, 2011), in accordance with the findings in this study. Salmonella spp., on the other hand, is a zoonotic bacteria that can infect most animals (Hasan et al., 2019) and several international standards demand absence of this microorganism in consumable products by animals and humans. It may also be found in decaying carcasses (Morris et al., 1970), however, this microorganism was not naturally observed in the carcasses used in this study. Salmonella spp. has been reported to be reduced in BSF larvae treatment, but the fate of $E$. coli is not consistent in previous studies. Therefore, they were chosen here as model microorganisms to evaluate the effect of treatment of aquaculture wastes.

Black soldier fly larvae treatment had strongest impact on Salmonella spp., with reductions of up to $6 \log _{10}$ observed in T1 and T2. Based on larval growth and process efficiency parameters, Salmonella spp. inactivation was also affected by time of contamination: the treatment that received three contaminated feedings (T3) displayed a $\mathrm{D}_{90}$ of 4.5 days, in comparison with 2.4 days in $\mathrm{T} 1$ and $\mathrm{T} 2$, which resulted in lower total inactivation $\left(\sim 3.3 \log _{10}\right.$ reduction) after 14 days in T3. A pronounced lag phase was observed in the effect on Salmonella spp. growth in T1-3, as the concentration started to be reduced within approximately 5-7 days after the beginning of the experiment (Figure 3A). Therefore, the difference in reduction potential of $\mathrm{T} 1$ and $\mathrm{T} 2$ compared with $\mathrm{T} 3$ seemed to be a consequence of adding contaminated substrate more than once (Figure 1).

A few studies have demonstrated that different pathogens in the Enterobacteriaceae family can be inactivated in BSF larvae treatment, using different feeding systems. For example, using a continuous fly reactor, in which BSF larvae were fed with inoculated substrate three times a week and prepupae was continuously collected, Lalander et al. (2015) observed significant reductions in Salmonella Typhimurium $\left(>7 \log _{10}\right)$, beginning after 2 weeks of treatment and persisting for the remainder of their 9-week experiment, while the impact on thermotolerant coliforms was small. The authors hypothesized that a continuous system could improve the hygienic quality of the treated material compared with a batch-mode system, due to possible interactions of an established microbial and fungal community. As shown in the present study, it is not possible to adopt this BSF larvae treatment as a sole hygienization method, regardless of the system 


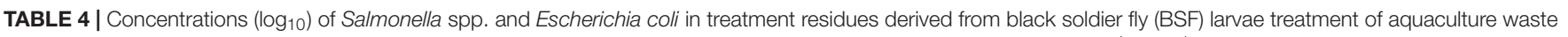
and bread, at the first (In) and fifth (Out) days of the regrowth trial, and values of the reduction constant $\left(k, \log _{10} C F U g^{-1} d_{a y}{ }^{-1}\right)$ and the mean log 10 reduction $\left(\Delta \log _{10} R e d\right)$ achieved.

\begin{tabular}{|c|c|c|c|c|c|c|c|c|}
\hline & \multicolumn{4}{|c|}{ Salmonella spp. $\left(\log _{10}\right)$} & \multicolumn{4}{|c|}{ E. coli $\left(\log _{10}\right)$} \\
\hline & In & Out & $\Delta \log _{10} R e d$ & $k$ & In & Out & $\Delta \log _{10} R e d$ & $k$ \\
\hline T1 & 6.76 & $4.14^{b}$ & $2.61^{a}$ & $-0.186^{a}$ & 5.80 & $3.44^{c}$ & $2.37^{a}$ & $-0.169^{a}$ \\
\hline $\mathrm{T} 2$ & 6.69 & $4.09^{b}$ & $2.60^{a}$ & $-0.185^{a}$ & 5.86 & $3.23^{c}$ & $2.63^{a}$ & $-0.187^{a}$ \\
\hline T3 & 6.87 & $4.56^{b}$ & $2.31^{a}$ & $-0.165^{a}$ & 6.05 & $4.22^{b}$ & $1.84^{b}$ & $-0.131^{a}$ \\
\hline CT & 7.04 & $7.11^{\mathrm{a}}$ & $-0.07^{b}$ & $0.005^{b}$ & 5.59 & $6.35^{\mathrm{a}}$ & $-0.76^{c}$ & $0.054^{b}$ \\
\hline
\end{tabular}

CT, wastes inoculated with pathogens without larvae; T1, larvae fed once with inoculated wastes; T2, larvae fed three times, with wastes inoculated only the first time; T3, larvae fed three times, with wastes inoculated all three times different letters column-wise indicate significant differences ( $p<0.05)$.

used, because, although some bacteria in the Enterobacteriaceae family are inactivated, the degree of inactivation is not sufficient to guarantee a completely safe end-product, regarding both larvae and treatment residues.

Gram-negative E. coli was inactivated over time up to $4 \log _{10}$, while in the study of Lalander et al. (2015), a small inactivation was verified for thermotolerant coliforms. Erickson et al. (2004) verified only a small reduction in $E$. coli at $27^{\circ} \mathrm{C}\left(1.5 \log _{10}\right)$ and a more significant reduction $\left(5 \log _{10}\right)$ at $32^{\circ} \mathrm{C}$ in one of the three feeding substrates (chicken manure) they evaluated. As reported by the authors of that study, such a strong inactivation of E. coli at $32^{\circ} \mathrm{C}$ in comparison to lower temperatures, might be due to increased concentration of uncharged ammonia in the manure, which is known to increase with temperature (Nordin et al., 2009). Zdybicka-Barabas et al. (2017) studied the immune response of BSF larvae challenged with Gram-positive (Micrococcus luteus) and Gram-negative (E. coli) bacteria, and verified that the larvae produce specific sets of antimicrobial peptides to fight those bacteria, while other microorganisms remained unaffected. In addition, Vogel et al. (2018) suggested that the immune response of BSF larvae is at least partly dietdependent, and that protein-rich diets might lead to stronger immune defenses. The authors found stronger antimicrobial activity against $E$. coli in larvae fed proteins, in comparison to larvae fed a plant oil-rich diet or a lignin-rich diet. In this sense, it is possible to assume that $E$. coli inactivation in the present study may have partly occurred due to excreted antimicrobial peptides induced by the influence of diet, which was protein-rich as fish carcasses were included.

No reduction in the Gram-positive bacteria Enterococcus spp. was found in this study (Figure 3C). Different types of antimicrobial peptides have been isolated from the BSF larvae that displayed significant effects against different bacteria strains. Choi et al. (2012) found antimicrobial peptides in methanol extracts of BSF larvae that showed antimicrobial properties against members of the Enterobacteriaceae family, but with no impact on Gram-positive bacteria, while Shin and Park (2019) successfully isolated attacin from BSF larvae, a type of antimicrobial peptide that has shown antimicrobial properties to selected Gram-negative and Gram-positive bacteria. However, in this last case, the antimicrobial substances were isolated from the larvae after an immunization process in which the production of these substances were induced in the larvae. Considering that
Lalander et al. (2013) found high levels of Enterococcus spp. in BSF larval gut, suggesting that this is not a threat to the larvae, it may be that the BSF larvae does not produce any antimicrobial substance effective against this microorganism as an immune response. Alternative, the conditions under which the experiment was undertaken or similar to the case for E. coli the substrate, did not induce the production of these peptides in this case. Furthermore, other properties may have an impact. Enterococcus spp. has specific characteristics in their cell wall that assures higher endurance, such as greater thickness, composition with more peptidoglycans in comparison to Gram-negative bacteria, and higher resistance to ruptures (Hancock et al., 2014).

Another impacting factor could have been the TAN concentrations, as they were higher in treatments containing larvae (T1-3) than in the control (CT) without larvae (Figure 2). In a study that evaluated Salmonella spp. inactivation using urea and ammonia, Fidjeland et al. (2016) obtained significant inactivation of this pathogen at different temperatures $\left(5-32^{\circ} \mathrm{C}\right)$ using high concentrations of ammonia (>50 mM). In the present study, TAN concentrations did not exceed $13 \mathrm{mM} \mathrm{kg}^{-1}$, thus it is possible to assume that the effect of TAN on pathogen inactivation was possibly less relevant than the direct action of the BSF larvae. Similarly, although substrate temperature was not investigated directly in our study, it may have influenced microbial survival, as thoroughly demonstrated by Liu et al. (2008).

\section{Bacteria Regrowth}

It is difficult to ensure that microorganisms are entirely eliminated when treating organic wastes, regardless of the method used, as bacterial regrowth may occur under appropriate conditions (e.g. moisture, temperature, and $\mathrm{pH}$ ), even after the end of treatment (Soobhany et al., 2017). The degree of maturity of compost has been demonstrated by Elving et al. (2010) to affect bacterial regrowth; they found negative correlations between the growth potential of Salmonella Typhimurium and the degree of maturity of an organic compost. The maturity of a material in a composting process (e.g. thermophilic composting and BSF larvae treatment) can be determined either by the self-heating capacity of the material (Brinton et al., 1994) or by assessing the $\mathrm{CO}_{2}$ and $\mathrm{NH}_{3}$ emissions 
in the material, using simple commercially available tests (Changa et al., 2003). The treatment residue from fly larvae composting has been found to be that of raw compost (Lalander et al., 2018), so it is thus unlikely that the maturity of the residue was a main driver for continued inactivation in this study.

Although the impact of antimicrobial substances may play a key role in the inactivation of selected microorganism in a BSF larvae treatment, as discussed above, it is not clear whether the material has to pass through the larval gut to be in contact with these substances or whether they are excreted by the larvae. In the studies that have isolated antimicrobial substances, the substances were isolated from the larvae. Additionally, interactions between BSF larvae intrinsic bacteria and the medium bacteria may occur and further affect the dynamics of these microorganisms over time (Wynants et al., 2018; Jiang et al., 2019). The regrowth trial demonstrated that, after inoculating more microorganisms into the treatment residues, inactivation continued to occur even in the absence of BSF larvae, suggesting that antimicrobial substances were present in the treatment residue, or even that larval microbiota somehow affected microorganisms' survival. The same patterns in inactivation of studied microorganisms that were seen in the composting phase was also seen in the regrowth trial, further supporting the hypothesis that antimicrobial substances excreted into the material (in this case treatment residue) contributed to the observed reduction in Salmonella spp. and E. coli.

\section{CONCLUSION}

Feeding regimes were found to have an impact in BSF larvae composting of aquaculture waste. Larvae growth, bioconversion and protein conversion ratios was higher when the same amount of aquaculture waste was provided three times during the 14days BSF larvae composting process as compared to when it was provided in a lump sum at the start of the treatment. Significant inactivation of Salmonella spp. (6 log) and E. coli $(3.5 \mathrm{log})$ were achieved when the substrate was provided as a lump sum at the start, but when the substrate was inoculated three times these reductions were less pronounced. Enterococcus spp. was not affected by the treatment regardless of feeding regime. Even when larvae was removed from the treatment residues, both Salmonella spp. and E. coli continued to be inactivated in the material for 5 days, suggesting that there are antimicrobial substances present in the fly larvae composted material. Whether these

\section{REFERENCES}

Banks, I. J., Gibson, W. T., and Cameron, M. M. (2014). Growth rates of black soldier fly larvae fed on fresh human faeces and their implication for improving sanitation. Trop. Med. Int. Health. 19, 14-22. doi: 10.1111/tmi.12228

Brinton, W. F., Evans, E., Droffner, M. L., and Brinton, R. B. (1994). A standardized dewar test for evaluation of compost self-heating. Biocycle 36, 1-16.

Carlos, C., Pires, M. M., Stoppe, N. C., Hachich, E. M., Sato, M. I. Z., Gomes, T. A. T., et al. (2010). Escherichia coli phylogenetic group determination and its application in the identification of the major animal source of fecal contamination. BMC Microbiol. 10:161. doi: 10.1186/1471-2180-10-161 substances originate from the larvae or from the larvae associated microbial community has to be investigated further. Regardless of the adopted feeding regimes, BSF larvae treatment cannot be considered a hygienization method, as it only improves the hygiene quality of the materials, thus it is recommended that both larval biomass and treatment residues undergo a post-treatment in order to ensure complete sanitization.

\section{DATA AVAILABILITY STATEMENT}

The datasets presented in this study can be found in online repositories. The names of the repository/repositories and accession number(s) can be found at: Mendeley Data repository http://dx.doi.org/10.17632/n52h7d4gk2.1.

\section{AUTHOR CONTRIBUTIONS}

IL: conceptualization, investigation, formal analysis, writing the original draft, and visualization. CL: conceptualization, investigation, formal analysis, resources, supervision, funding acquisition, and writing - review and editing. RV: conceptualization and supervision. BV: conceptualization, resources, supervision, funding acquisition, and writing - review and editing. All the authors contributed to the article and approved the submitted version.

\section{FUNDING}

IL was granted with a Ph.D. sandwich scholarship from Coordenação de Aperfeiçoamento de Pessoal de Nível Superior Brazil (CAPES) (process number 88881,189798/2018-01). Funding for this study was provided by Vinnova, Sweden's innovation agency within the project Five tons sustainable fish in the counter (2019-00854) received within the call Challenge-Driven Innovation - Stage 2.

\section{ACKNOWLEDGMENTS}

The authors thank Fazer and Willys Supermarket for supplying the bread waste, Nordic Trout for providing the aquaculture waste used in this study, and Lovisa Lindberg for the technical assistance.

Changa, C. M., Wang, P., Watson, M. E., Hoitik, H. A. J., and Michel, F. C. Jr. (2003). Assessment of the reliability of a commercial maturity test kit for composted manures. Compost Sci. Util. 11, 125-143. doi: 10.1080/1065657X. 2003.10702119

Choi, W. H., Yun, J. H., Chu, J. P., and Chu, K. B. (2012). Antibacterial effect of extracts of Hermetia illucens (Diptera: Stratiomyidae) larvae against gramnegative bacteria. Entomol. Res. 42, 219-226. doi: 10.1111/j.1748-5967.2012. 00465.x

Coluccio, A. E., Rodriguez, R. K., Kernan, M. J., and Neiman, A. M. (2008). The yeast spore wall enables spores to survive passage through the digestive tract of Drosophila. PLoS One 3:e2873. doi: 10.1371/journal.pone.0002873 
Elving, J., Ottoson, J. R., Vinnerås, B., and Albihn, A. (2010). Growth potential of faecal bacteria in simulated psychrophilic/mesophilic zones during composting of organic waste. J. Appl. Microbiol. 108, 1974-1981. doi: 10.1111/j.1365-2672. 2009.04593.x

Erickson, M. C., Islam, M., Sheppard, G., Liao, J., and Doyle, M. P. (2004). Reduction of Escherichia coli O157:H7 and Salmonella enterica serovar Enteritidis in chicken manure by larvae of the black soldier fly. J. Food Protect. 67, 685-690. doi: 10.4315/0362-028X-67.4.685

Erondu, E. S., and Anyanwu, P. E. (2005). Potential hazards and risks associated with the aquaculture industry. Afr. J. Biotechnol. 4, 1622-1627. doi: 10.4314/ ajfand.v4i13.71775

FAO (2018). The State of World Fisheries and Aquaculture 2018 - Meeting the Sustainable Development Goals. Roma: FAO.

Fidjeland, J., Nordin, A., and Vinnerås, B. (2016). Inactivation of Ascaris eggs and Salmonella spp. in fecal sludge by treatment with urea and ammonia solution. J. Water. Sanit. Hyg. De 6, 465-473. doi: 10.2166/washdev.2016.017

Ghaly, A. E., Dave, D., Budge, S., and Brooks, M. S. (2010). Fish spoilage mechanisms and preservation techniques: review. Am. J. Appl. Sci. 7, 859-877. doi: 10.3844/ajassp.2010.859.877

Grudziñsk, M., Pietruszka, A., and Sawicki, W. (2015). Anaerobic digestion in sanitization of pig slurry and biomass in agricultural biogas plant. J. Microbiol. Biotechnol. Food. Sci. 4, 524-526. doi: 10.15414/jmbfs.2015.4.6.524-526

Hachich, E. M., Bari, M. D., Christ, A. P. G., Lamparelli, C. C., Ramos, S. S., and Sato, M. I. Z. (2012). Comparison of thermotolerant coliforms and Escherichia coli densities in freshwater bodies. Braz. J. Microbiol. 43, 675-681. doi: 10.1590/ S1517-83822012000200032

Hancock, L. E., Murray, B. E., and Sillanpää, J. (2014). "Enterococcal cell wall components and structures," in Enterococci: From Commensals to Leading Causes of drug Resistant Infection, eds M. S. Gilmore, D. B. Clewell, Y. Ike, and N. Shankar (Boston: Massachusetts Eye and Ear Infirmary).

Hasan, R., Nordin, A. C., Shakoor, S., Keenum, I., and Vinnerås, B. (2019). "Salmonella, enteric fevers, and salmonellosis," in Global Water Pathogen Project, eds J. B. Rose and B. Jiménez-Cisneros (Lansing, MI: UNESCO), doi: 10.14321/waterpathogens.27

Jiang, C. L., Jin, W. Z., Tao, X. H., Zhang, Q., Zhu, J., Feng, S. Y., et al. (2019). Black soldier fly larvae (Hermetia illucens) strengthen the metabolic function of food waste biodegradation by gut microbiome. Microb. Biotechnol. 12, 528-543. doi: 10.1111/1751-7915.13393

Lalander, C., Diener, S., Magri, M. E., Zurbrügg, C., Lindström, A., and Vinnerås, B. (2013). Faecal sludge management with the larvae of the black soldier fly (Hermetia illucens) - from a hygiene aspect. Sci. Total. Environ. 45, 312-318. doi: 10.1016/j.scitotenv.2013.04.033

Lalander, C., Fidjeland, J., Diener, S., Eriksson, S., and Vinnerås, B. (2015). High waste-to-biomass conversion and efficient Salmonella spp. reduction using black soldier fly for waste recycling. Agron. Sustain. Dev. 35, 261-271. doi: 10.1007/s13593-014-0235-4

Lalander, C., Nordberg, Å, and Vinnerås, B. (2018). A comparison in productvalue potential in four treatment strategies for food waste and faeces - assessing composting, fly larvae composting and anaerobic digestion. GCB Bioenergy 10, 84-91. doi: $10.1111 /$ gcbb. 12470

Leroi, F., and Joffraud, J. J. (2011). "Microbial degradation of seafood," in Aquaculture Microbiology and Biotechnology, 2nd Edn, eds D. Montet and R. C. Ray (Enfield: Science Publishers), 47-72. doi: 10.1201/b10923-4

Liu, Q., Tomberlin, J. K., Brady, J. A., Sanford, M. R., and Yu, Z. (2008). Black soldier fly (Diptera: Stratiomyidae) larvae reduce Escherichia coli in dairy manure. Environ. Entomol. 37, 1525-1530. doi: 10.1603/0046-225X-37.6.1525

Lopes, I. G., Lalander, C., Vidotti, R. M., and Vinnerås, B. (2020). Using Hermetia illucens larvae to process biowaste from aquaculture production. J. Clean. Prod. 251:119753. doi: 10.1016/j.jclepro.2019.119753

Lopes, I. G., Souza, L. F., Cruz, M. C. P., and Vidotti, R. M. (2019). Composting as a strategy to recycle aquatic animal waste: case study of a research centre in São Paulo State. Brazil. Waste Manage. Res. 37, 590-600. doi: 10.1177/ $0734242 X 19830170$

Love, D. C., Fry, J. P., Milli, M. C., and Neff, R. A. (2015). Wasted seafood in the United States: quantifying loss from production to consumption and moving toward solutions. Glob. Environ. Chang. 35, 116-124. doi: 10.1016/j.gloenvcha. 2015.08.013

Marchaim, U., Gelman, A., and Braverman, Y. (2003). Reducing waste contamination from animal-processing plants by anaerobic thermophilic fermentation and be flesh fly digestion. Appl. Biochem. Biotech 109, 107-115. doi: 10.1385/abab:109:1-3:107

Mol, S., and Tosun, S. Y. (2011). The quality of fish from retail markets in Istanbul. Turkey. J. Fish. Sci. 5, 16-25.

Morris, G. K., Martin, W. T., Shelton, W. H., Wells, J. G., and Brachman, P. S. (1970). Salmonellae in fish meal plants: relative amounts of contamination at various stages of processing and a method of control. Appl. Microbiol. 19, 401-408. doi: 10.1128/aem.19.3.401-408.1970

Nordin, A., Ottoson, J. R., and Vinnerås, B. (2009). Sanitation of faeces from source-separating dry toilets using urea. J. Appl. Microbiol. 107, 1579-1587. doi: 10.1111/j.1365-2672.2009.04339.x

Park, S. I., Chang, B. S., and Yoe, S. M. (2014). Detection of antimicrobial substances from larvae of the black soldier fly, Hermetia illucens (Diptera: Stratiomyidae). Entomol. Res. 44, 58-64. doi: 10.1111/1748-5967.12050

R Core Team (2019). R: A Language and Environment for Statistical Computing. Vienna: R Foundation for Statistical Computing.

Setti, L., Francia, E., Pulvirenti, A., Gigliano, S., Zaccardelli, M., Pane, C., et al. (2019). Use of black soldier fly (Hermetia illucens (L.), Diptera: Stratiomyidae) larvae processing residue in peat-based growing media. Waste. Manage. 95, 278-288. doi: 10.1016/j.wasman.2019.06.017

Shawyer, M., and Pizzali, M. (2003). "The use of ice o small fishing vessels," in Food and Agriculture Organization of the United Nation, eds M. Shawyer and M. Pizzali (Rome: FAO), 1-34.

Shin, H. S., and Park, S. I. (2019). Novel attacin from Hermetia illucens: cDNA cloning, characterization, and antibacterial properties. Prep. Biochem. Biotech. 4, 279-285. doi: 10.1080/10826068.2018.1541807

Soobhany, N., Mohee, R., and Garg, V. K. (2017). Inactivation of bacterial pathogenic load in compost against vermicompost of organic solid waste aiming to achieve sanitation goals: a review. Waste. Manage. 64, 51-62. doi: 10.1016/j. wasman.2017.03.003

Sousa, C. L., Freitas, J. A., Lourenço, L. F. H., Araujo, E. A. F., and Joele, M. R. S. P. (2014). Microbiological contamination of surfaces in fish industry. Afr. J. Microbiol. Res. 8, 425-431. doi: 10.5897/AJMR2013.6319

Vogel, H., Müller, A., Heckel, D. G., Gutzeit, H., and Vilcinskas, A. (2018). Nutritional immunology: diversification and diet-dependent expression of antimicrobial peptides in the black soldier fly Hermetia illucens. Dev. Comp. Immunol. 78, 141-148. doi: 10.1016/j.dci.2017.09.008

Wang, Y. S., and Shelomi, M. (2017). Review of black soldier fly (Hermetia illucens) as animal feed and human food. Animals 6:91. doi: 10.3390/foods610 0091

Wynants, E., Frooninckx, L., Crauwels, S., Verreth, C., De Smet, J., Sandrock, C., et al. (2018). Assessing the microbiota of black soldier fly larvae (Hermetia illucens) reared on organic waste streams on four different locations at laboratory and large scale. Microb. Ecol. 77, 913-930. doi: 10.1007/s00248-0181286-x

Zdybicka-Barabas, A., Bulak, P., Polakowski, C., Bieganowski, A., Waśko, A., and Cytryñska, M. (2017). Immune response in the larvae of the black soldier fly Hermetia illucens. ISJ Invert. Surviv. J. 14, 9-17. doi: 10.25431/1824-307X/isj. v14i1.9-17

Conflict of Interest: The authors declare that the research was conducted in the absence of any commercial or financial relationships that could be construed as a potential conflict of interest.

Copyright (c) 2020 Lopes, Lalander, Vidotti and Vinnerås. This is an open-access article distributed under the terms of the Creative Commons Attribution License (CC BY). The use, distribution or reproduction in other forums is permitted, provided the original author(s) and the copyright owner(s) are credited and that the original publication in this journal is cited, in accordance with accepted academic practice. No use, distribution or reproduction is permitted which does not comply with these terms. 